\title{
INTERCULTURALIDAD Y CONOCIMIENTO ANDINO: REFLEXIONES ACERCA DE LA MONOCULTURA EPISTEMOLÓGICA
}

\author{
Josef Estermann \\ Universidad de Lucerna, Suiza
}

\begin{abstract}
Resumen:
Mediante los procesos coloniales y neocoloniales, Occidente ha sabido imponer una hegemonía epistemológica a todo el mundo; lo cual repercute en los estándares académicos del saber, títulos, procedimientos y contenidos. En el presente artículo, el autor somete esta supuesta monocultura epistemológica a una deconstrucción intercultural. Las universidades europeas y latinoamericanas deben mucho a las anteriores, de la China, la India y las del ámbito árabe. Por otro lado, Abya Yala (nombre indígena de América) tenía antes de la Conquista ya una rica tradición epistemológica con instituciones del saber. La interculturación de la epistemología permite incluir en el conocimiento humano saberes muy distintos, entre ellos los saberes indígenas de los Andes.
\end{abstract}

\section{Palabras clave:}

Epistemología, Abya Yala, filosofía andina, universidad, conocimiento, interculturalidad. 


\title{
Interculturality and Andean Knowledge: Reflections on the Epistemological Monoculture
}

\begin{abstract}
:
Through colonial and neocolonial processes, the West has been able to impose epistemological hegemony on the whole world, which has repercussions on the academic standards of knowledge, titles, procedures and content. In the present article, the author analyzes this supposed epistemological monoculture critically by means of intercultural deconstruction. European and Latin American universities owe much to the previous ones in China, India and the Arab world. On the other hand, Abya Yala (such is the indigenous name for "America") already had a rich epistemological tradition with institutions of knowledge before the Conquest. The interculturation of epistemology makes it possible to include very different types of knowledge, including the indigenous knowledge of the Andes.
\end{abstract}

\section{Keywords:}

Epistemology, Abya Yala, Andean philosophy, university, knowledge, interculturality.

\section{Josef Estermann}

Doctor en filosofía y licenciado en teología, con amplia experiencia en los Andes del Perú y Bolivia. Es actualmente docente de la Universidad de Lucerna y responsable de Bases e Investigación en COMUNDO (Suiza). Sus campos de investigación son: filosofía y teología andinas, filosofía intercultural, teología de la liberación, buen vivir andino, post-desarrollismo, descolonización. Entre sus publicaciones $(1998 ; 2018)$ destacan: Filosofía Andina: Estudio intercultural de la sabiduría autóctona andina; Lima-Cusco: Paulinas, Seminario San Antonio Abad.

Correo: josefestermann@hotmail.com 


\section{Introducción}

En el marco por el debate decolonial, la cuestión de la epistemología recobra cada vez más ímpetu. Este hecho no debe de sorprender en la era de la información y del saber como capital económico del futuro, tal vez como primer medio de producción. Desde el célebre adagium de Francis Bacon de que «saber es poder (knowledge is power)», sabemos que el monopolio o al menos la hegemonía con respecto al conocimiento, es uno de los factores que permite entender la historia hasta ahora exitosa de Occidente en los campos de las ciencias y la tecnología. La llamada guerra comercial desatada últimamente por la administración de Washington, en principio contra China, tiene como objetivo principal la protección de la propiedad intelectual y, por tanto, de un conocimiento producido por la élite del Silicon Valley y el Instituto Tecnológico de Massachusetts (MIT, por sus siglas en inglés). Este ejemplo nos demuestra de por sí que la cuestión de la epistemología no puede ser tratada fuera del ámbito cultural o, en un sentido más político, civilizacional.

\section{Del pluralismo epistemológico a la monocultura del saber}

El predominio de Occidente en el campo del saber a través de la tecnociencia, no siempre ha sido un hecho incontestable; antes del Renacimiento europeo, el Viejo Continente no jugaba un papel predominante ni mucho menos único en la producción y reproducción del saber. Aunque las universidades medievales (París, Boloña, Oxford, Colonia, Salamanca) hayan dado un impulso decisivo para el desarrollo de las ciencias y la filosofía europeas, eran en gran medida copias más o menos creativas de las casas del saber árabes. Las universidades más antiguas provienen de la China, de la India, de Persia y de lo que se conoce bajo el nombre de Media Luna Fértil ${ }^{1}$

La Universidad de Hunan en la actual China es considerada la universidad más antigua del mundo. Se encuentran registros de la

1 En nomenclatura eurocéntrica, se habla de Medio Oriente y Oriente Próximo. En forma menos eurocéntrica, es la franja en forma de media luna que se extiende desde Mesopotamia, pasando por Siria hasta llegar a Egipto. 
existencia de la Escuela Superior Imperial (Shangyang) durante el período Yu (2.257 a.C. - 2.208 a.C.) y la actual Universidad de Nanjing remonta su origen a la Academia Central Imperial de Nanking fundada en el año 258 d.C. La ya mencionada Universidad de Hunan (Changsha) guarda una continuidad innegable, incluso geográfica, con la histórica Academia Yuelu, fundada en el año 976 d. C.²

La Universidad de Takshashila, fundada en Taxila (Pakistán) alrededor del siglo VII a.C., entregaba títulos de graduación. ${ }^{3}$ La Universidad de Nalanda, fundada en Bihar (India) alrededor del siglo $\mathrm{V}$ a.C., también entregaba títulos académicos y organizaba cursos de postgrado. En comparación con estas universidades chinas, Platón fundó su Academia recién en el año 387 a.C. en Atenas (cerrada en 529 por el emperador romano Justiniano), ${ }^{4}$ la que ha sido el modelo paradigmático para la fundación de la universidad en la Europa medieval y —en menor medida - el Liceo aristotélico, ${ }^{5}$ espacios de encuentro entre las élites intelectuales y filosóficas, con el fin de debatir los últimos hallazgos científicos y especulativos de la época.

2 La Academia Yuelu fue fundada en el año 976, noveno año del reinado de la dinastía Song y fue una de las cuatro academias imperiales de estudios superiores. Está postulada como la universidad más antigua del mundo entre las existentes. Los discípulos de Confucio, Zhu Xi y Zhang Shi estudiaron en esta institución. En 1903 la academia se convirtió en universidad y en 1925 se estableció en el lugar la Universidad de Hunan. Desde su fundación, la academia Yuelu ha gozado de un elevado prestigio como institución cultural y centro de actividades académicas. Ha sido testigo de más de mil años consecutivos de historia y es la única de las antiguas academias chinas de estudios clásicos que se ha convertido en una institución moderna de estudios superiores. Como parte integrante de la Universidad de Hunan, la academia se ha convertido en un centro de investigación del idioma Han y es uno de los principales centros académicos y culturales de China.

3 Taxila es un importante lugar arqueológico en Pakistán que contiene las ruinas de la ciudad de Gandhara y de la universidad de Takshashila (también Takkasila o Taxila), un importante centro de enseñanza védico/hinduista y budista del siglo $\mathrm{V}$ a.C. al siglo II. Pertenecía a la influencia de dinastías de la India. Se considera la universidad más antigua del mundo, entre las ya no existentes.

4 Escuela fundada por Platón en el 387 a.C. y que permaneció activa hasta el año 529. Se trata de la escuela filosófica de mayor tradición y mayores cambios experimentados.

${ }^{\text {El }}$ primer siglo de su existencia marca la fidelidad al maestro, es la denominada Antigua Academia, como escuela de Espeusipo, inmediato sucesor de Platón, Jenócrates, Pulmón, Crantor y Crates de Atenas. El segundo período o Academia Media, dura desde 315 hasta 241 a. C.; su máximo exponente es Arcesilao y se caracteriza por la introducción del escepticismo, influido por Pirrón, combatiendo el estoicismo y el epicureísmo. Finalmente, la Academia Nueva abandona el escepticismo y se centra en el eclecticismo, mezclando aristotelismo y estoicismo con el platonismo. Sus principales representantes son Filón de Larisa, maestro de Cicerón, y sobre todo Antíoco de Ascalón. Finalmente, la Academia fue absorbida por el neoplatonismo de Plotino. Su principal representante fue Proclos (410-485), natural de Atenas.

En el Renacimiento, la Academia platónica fue reestablecida en Florencia, fundada en 1440 por el mecenas Cosme de Médicis.

5 Aristóteles fundó el Liceo (en honor al dios Apolon Liceo) en 336 a.C. Funcionaba hasta su clausura por el Emperador Justiniano en 529 d.C., aunque sufría diferentes saqueos y destrucciones. 
Durante el siglo IV y hasta finales del siglo $\mathrm{V}$ d.C. funcionaban las famosas escuelas de Edesa y Nisibis fundadas por cristianos sirios (nestorianos), organizadas como comunidades de maestros y dedicadas a la exégesis bíblica. En 489, los cristianos nestorianos fueron expulsados del Imperio Bizantino, por lo que, liderados por Nestorio, Patriarca de Constantinopla (428-431), ${ }^{6}$ decidieron trasladarse a Persia, donde eran bien recibidos, para establecer la Escuela de Medicina de Gondishapur, que se haría famosa en todo el mundo. ${ }^{7}$

Poco después, en 529, el emperador romano cristianizado Justiniano cerró la Academia platónica de Atenas y el Liceo peripatético, profundizando de esta manera la intolerancia y resistencia hacia los centros de estudios (paganos) en el Imperio Romano Oriental. Entre 637 y 651, los musulmanes árabes derrotaron al Imperio Persa de los sasánidas ${ }^{8}$ y se apoderaron de Gondishapur. A finales del siglo VIII la Escuela de Gondishapur se trasladaba a Bagdad, donde se reorganizaría como el Bayt al Hikma (la 'Casa de la Sabiduría') para traducir las obras científicas de médicos y filósofos como Aristóteles, Hipócrates, Galeno y Dioscórides, que en los siglos XI y XII llegarían a Occidente a través de la península hispánica.

Durante el siglo VIII también aparecían los hospitales que se vincularían estrechamente con las escuelas de Medicina, terminando por definir un modelo empirista, laico, tolerante y riguroso de universidad, que dará fama mundial a aquellos establecimientos e impactaría en el modelo de las primeras universidades europeas. Existen registros sobre los estrictos exámenes y numerosos cursos para los estudiantes de la Escuela de Medicina de El Cairo que tenían que aprobar para quedar autorizados a ejercer la medicina.

El nuevo modelo adoptado por las universidades árabes y persas se caracterizó por el rigor en el estudio, y muy especialmente por la investigación y la enseñanza de la medicina. Este modelo inspiraría las universidades

\footnotetext{
6 En 330 d.C., el nombre Bizancio, ciudad creada por los griegos en 667 a.C., fue cambiado a Constantinópolis o Constantinopla, en homenaje al emperador romano Constantino el Grande (227-337). El imperio correspondiente se llamaba, después de la caída del Imperio Romano occidental, hasta la conquista por los otomanes en 1493 Imperio Romano Oriental, cuya capital Constantinopla se conocía simplemente bajo el nombre de la ciudad. Este último hecho daba posteriormente el nombre turco Estambul (Istanbul) a la ciudad, deformación de eis tên polin ('en la ciudad'). Del Imperio Bizantino recién se empezó a hablar en la historiografía del siglo XVI.

7 La iglesia nestoriana defendió en el Concilio de Éfeso (431), contra Cirilo de Alejandría, la confluencia en Jesucristo de dos personas separadas, además de la característica de María como christotokos, es decir 'madre de Cristo' (y no theotokos, 'Madre de Dios'). Como consecuencia de la expulsión del Imperio Romano Oriental (o Bizantino), llegaron no solamente a Persia e India, sino a Mongolia y China, donde se ha encontrado el famoso monolito nestoriano, en tres idiomas. Hoy, siguen existiendo iglesias nestorianas en Irak, Irán, India y China. 8 Es el nombre del Segundo Imperio Persa, durante su cuarta dinastía irania (226-651 d.C.).
} 
europeas modernas. Algunas de las más famosas universidades árabes y persas antiguas fueron:

- $\quad$ Bagdad (Bayt al Hikma), fundada a fines del siglo VIII: allí enseñó e investigó el famoso sabio Al-Razi (Rhazes) entre 865 y 925.

- Córdoba (España), fundada en el siglo VIII: allí enseñó e investigó Abulcasis $^{9}$ (936).

- $\quad$ El Cairo (Al-Azhar), fundada en 988: allí enseñaron Maimónides (11351204) e Ibn Jaldún (1332-1406), entre otros. Ha continuado funcionando ininterrumpidamente hasta nuestros días.

- $\quad$ Salerno (Italia), fundada en el siglo X: modelo directo de muchas de las universidades europeas existentes en la actualidad.

- Damasco: a partir de la fundación de la Escuela de Medicina en 1158 se convirtió en el centro científico de Siria.

- $\quad$ Samarcanda: contaba con un importante observatorio (Ulugh Beg) en 1420.

Las universidades árabes comenzaron a decaer cuando Córdoba cayó en poder de los españoles en 1236 y Bagdad cayó en poder de los mongoles en 1258. Sin embargo, ello no impidió que allí apareciera Ibn Jaldún, ${ }^{10}$ señalado como el primer sociólogo de la historia y profesor de la Universidad de AlAzhar (El Cairo).

Por otro lado, también en Abya Yala (nombre indígena de América) existían en la época de la Edad Media europea ${ }^{11}$ unas ricas tradiciones del saber, tanto en Mesoamérica como en la región andina. En el caso del Imperio Azteca (o Mexica) que duró desde la fundación de Tenochtitlán (1325) hasta la Conquista española (1521) apenas dos siglos, la organización del saber puede competir sin problemas con la situación europea de la época. Aunque el escolasticismo académico del Viejo Continente parezca mucho más refinado y estructurado, se trataba de un saber altamente elitista (apenas un 2\% sabía leer y escribir) y especulativo-religioso.

\footnotetext{
9 Abū l-Qāsim Chalaf ibn ‘Abbās az-Zahrāwī (936-1013).

${ }_{10}$ Abū Zayd Abd ar-Raḥmān ibn Muḥammad ibn Jaldūn al-Hadramī, conocido habitualmente como Abenjaldún o Ibn Jaldún (también escrito Ibn Khaldun, Ibn Khaldoun o Abenjaldun), nacido el 27 de mayo de 1332 y fallecido el 19 de marzo de 1406, fue un famoso historiador y sociólogo árabe nacido en lo que hoy es Túnez y de origen andalusí. Es considerado como uno de los fundadores de la moderna historiografía, sociología y economía. Es fundamentalmente conocido por su obra Muqaddima o Prolegómenos a su vasta historia de los árabes, que constituye un temprano ensayo de filosofía de la historia y de sociología, disciplina esta última de la que a menudo es considerado antecesor.

11 La periodización académicamente aceptada en Antigüedad, Edad Media y Modernidad refleja una óptica eurocéntrica, por lo que urge indicar la relatividad cultural mediante el adjetivo correspondiente. Esto abre, desde la perspectiva intercultural, la posibilidad de modernidades no-occidentales.
} 
En la educación azteca (o nahua), la educación universal obligatoria de los hijos hasta la edad de veintisiete años estaba en manos de sus padres, pero supervisada por las autoridades de su calpulli (unidad social nahua). Parte de esta educación involucraba aprender una colección de discursos, llamada huehuetlahtolli (palabras de los ancianos), que representaban los ideales de la sociedad azteca. A la edad de 14 o 15 años se les enviaba oficialmente a la escuela o academia, dependiendo la clase social, género o de sus talentos. Los hijos de quienes eran jueces o gobernantes recibían el cuidado de ayas o ayos, quienes daban instrucción en cuanto a buenas costumbres y modales.

Hubo dos tipos de escuelas entre los aztecas: el telpochcalli ${ }^{12}$ para los estudios prácticos y militares, educación impartida por los más ancianos o los guerreros veteranos del calpulli; y el calmélac ${ }^{13}$ para el aprendizaje especializado en la escritura, la astronomía, la tecnología y liderazgo. El aprendizaje de estos conocimientos requería de gran disciplina y eran de mayor profundidad. Ambos tipos de escuelas se complementaban para lograr los objetivos comunitarios aztecas. En el telpochcalli también se impartía educación a las mujeres, pero se centraba principalmente en rituales religiosos. Sin embargo, tanto hombres como mujeres debían adquirir conocimientos generales sobre música, baile, historia, discursos públicos, entre otras cosas.

En el calmélac los estudiantes eran principalmente hijos de nobles y se separaba a los hombres de las mujeres; pero existen algunos registros de alumnos excepcionales de clases bajas a los que se les llegó a permitir estudiar en el calmélac. Debían aprender rigurosamente a interpretar los libros y las artes pictográficas. Los libros que debían conocer eran el Tonalámatl (Libro de los días), calendario adivinatorio de 260 días con tablas de adivinación y ciclos astronómicos; el Xiuhámatl (Libro de lo sucedido), libro que registraba toda la historia del pueblo azteca; y el Libro de los sueños, que correspondía al ámbito de la adivinación de los sacerdotes. Entre otras materias que se enseñaban estaban la poesía, matemática, retórica, música, leyes, astronomía, historia, arquitectura y el arte de la guerra.

En las culturas maya - que no formaban un imperio tal como los aztecas o incas-, la organización del saber en la época clásica (250-900 d.C.) se regía tanto por parámetros religiosos como seculares y por la complementariedad de género. En comparación con el caso azteca, la educación era un asunto mucho menos democrático, lo que repercutía en una diferenciación del conocimiento adquirido según el rol social y el género. En el período clásico y posclásico, los mayas mantenían diversos sitios como palacios, milpas, ${ }^{14}$ templos, campos

\footnotetext{
${ }^{12}$ Del náhuatl calli ('casa') y telpoch ('mancebo'): 'casa de los mancebos'.

${ }^{13}$ Del náhuatl calli ('casa'), mecatl ('morador') y -c ('lugar').

14 Del náhuatl milli, ,heredad' y pan, ,en', sobre'.
} 
de batallas, pirámides y plazas, entre otros, que se consideraban lugares educativos (Madrigal Frías 2011). En el período postclásico, se establece la Kambesaj Naj (Casa para enseñary aprender) y la Popol Na (Casa de comunidad), donde una autoridad dirigía los actos educativos. ${ }^{15}$

Otro hecho relevante para nuestro propósito es que en el idioma maya están contempladas palabras y terminologías que tratan sobre el proceso de educativo: Aj Ka'anbal ('alumno'), Aj Kambesaj ('maestro'), Ma'Ojelil ('ignorancia'), Ts'iib ('escribir'), K'aanbal ('aprender'), E'saj ('enseñar'), Weet Ka'anbal ('condiscípulo'). El Popol Vuh (Libro de la comunidad) es el libro de los conocimientos mayas más conocidos que manifiesta un alto grado de la ciencia maya con respecto a la astronomía, agricultura y matemáticas, que iguala a los conocimientos árabes de la misma época y supera por mucho los conocimientos empíricos de la Edad Media europea.

En el caso del imperio incaico o Tawantinsuyu, que en su forma de apogeo duró apenas un siglo — desde la fundación por Pachakutiq en 1438 hasta la Conquista española en 1533- la adquisición de conocimiento y la organización del saber jugaban un rol preponderante. Entre los campos del saber dominaban la tecnociencia militar, la astronomía, la medicina, la agrotecnología, la contabilidad matemática e inclusive sistemas de escritura ligados a los khipu.

En el Tawantinsuyu existieron dos tipos de educación, los Yachaywasi (Casas del saber) y los Aqllawasi (Casas de las escogidas) como centros de formación para los hombres y mujeres privilegiados respectivamente, y la educación familiar. Durante el incanato, la educación fue uno de los aspectos fundamentales sobre el cual descansaron los aparatos organizativos y los aparatos productivos del imperio incaico. En los Yachaywasi se enseñaba todo tipo de conocimientos y destrezas para mantener y desarrollar la estructura política, económica y social del Tawantinsuyu. La enseñanza estaba a cargo de los amautas que eran los hombres más ilustrados de la época.

La educación en este centro de estudios y preparación se orientó, básicamente, a cuatro aspectos: la lengua (runa simi), que incluía gramática, retórica, poesía y teatro, y posiblemente, muy similar a las artes liberales de la escolástica europea medieval, la religión, la filosofía cosmogónica, y la astronomía. Los jóvenes de la nobleza iniciaban su preparación en el Yachaywasi a partir de los 13 años; completada su educación a los 19 años aproximadamente, se realizaba una ceremonia especial llamada Warachikuy ('ponerse la trusa') como señal de madurez y virilidad.

15 Según el Diccionario de Motul, popol na significa 'casa de comunidad donde se juntan a tratar de cosas de república’. Gómez Navarrete, Javier (1998). 
Aparentemente, también pertenecía a este tipo de educación el manejo de los khipu, es decir los conocimientos matemáticos básicos y posiblemente las bases de un sistema gráfico aún no decodificado por completo. Para mujeres jóvenes selectas, como ya se ha señalado, el Aqllawasi era el lugar de una educación especial instruida por las mamakuna. Las aqllas ('mujeres escogidas') se formaban en actividades productivas, particularmente en la textilería y preparación de chicha, y estaban obligadas a prestar servicios laborales al Estado.

La educación familiar se refiere a la educación del pueblo incaico en un sentido más práctico.

Esta pluralidad epistémica transcultural, en la misma época del surgimiento de la universidad europea, llegó a su fin con el imperialismo europeo, el reduccionismo cartesiano y la imposición en un nivel global de los estándares del saber occidental a lo largo de los subsiguientes siglos.

\section{La imposición global del modelo europeo-occidental}

Aunque la fundación de las primeras universidades europeas en los siglos XI al XIII ${ }^{16}$ debía mucho a la larga tradición árabe y persa, en el Renacimiento empezó a desconocerse el pasado intercultural e interreligioso de lo que iba a imponerse como modelo único del saber en la modernidad occidental. Las universidades medievales —organizadas en torno al Studium Generale de las Artes liberales, de la filosofía, teología, medicina y derecho- todavía mantenían el espíritu de un saber integral y transdisciplinario, de una diversidad (versitas) epistemológica y metodológica bajo un solo (unum) techo. ${ }^{17}$

Se sobreentiende que las universidades medievales europeas y las que fueron exportadas al Nuevo Mundo se organizaban en torno a la teología como domina scientiarum ('señora de las ciencias') y la filosofía como ancilla

${ }_{16}$ Las primeras fueron Bolonia (Italia) en 1089, que recibe el título de Universidad en 1317; Oxford (Inglaterra) en 1096; París (Francia) en 1150, que recibe el título de Universidad en 1256; Módena (Italia) en 1175; Cambridge (Inglaterra) alrededor de 1208; Palencia (España) en 1208; Salamanca (España) en 1218; Universidad de Padua (Italia) en 1223; Universidad de Nápoles Federico II (Italia) en 1224; Universidad de Toulouse (Francia) en 1229.

17 Tomás de Aquino, por ejemplo, era todavía perfectamente consciente de la deuda intelectual para con los intelectuales árabes, los traductores de la Escuela de Toledo y los filósofos aristotélicos musulmanes como Avicena (Abū Alī al-Husain ibn Abd Allāh ibn Sīnā) y Averroes ('Abü l-Walīd'Aḥmad ibn Muḥammad ibn Rušd). Aunque los combatía en el campo teológico y filosófico, no hubiera sido posible su síntesis intelectual sin la mediación de las universidades árabes. 
theologiae ('sirvienta de la teología'). Con la Conquista de Abya Yala por los españoles (y más tarde los portugueses), se establecieron pronto las primeras universidades en suelo americano, en el espíritu de la Contrarreforma y de la Reconquista (frente a la ocupación musulmana), vigente en España del siglo XVI.

La conquista militar y política requería de un apoyo intelectual para defender la verdadera $f e$ y la cultura española. Pronto llegaron al Nuevo Mundo españoles de todos los niveles culturales, incluyendo sacerdotes y laicos con formación universitaria. Las primeras universidades fundadas en América Latina son - como es de conocimiento general- la Universidad de Santo Tomás de Aquino en Santo Domingo en la isla Hispaniola (1538), ${ }^{18}$ la Universidad de San Marcos en Lima (1551), la Universidad de México (1551) y la Universidad Santo Tomás de Santa Fe de Bogotá (1580).

El propósito principal de la fundación de estas universidades era aprovisionar a las colonias españolas de profesionales en los campos de la teología (incluyendo la filosofía), medicina y derecho, de acuerdo con el canon medieval de las ciencias. Sin embargo, el objetivo de fondo, muchas veces de forma implícita e inconsciente, era el de asegurarse la perpetuación del modelo civilizatorio occidental, en su forma de un catolicismo escolástico renacentista. ${ }^{19}$ Políticamente, las nuevas universidades sirvieron para establecer y fortalecer una élite criolla que iba a defender con argumentos científicos la empresa colonial en todos sus aspectos.

Hasta más allá del siglo XVIII, la mayoría de las universidades en América Latina replicaban el escolasticismo aún vigente en España, sin introducir a los pensadores modernos del racionalismo y empirismo europeo. Se trató de contrarrestar a las olas protestante y libertaria encarnadas por el pensamiento de los filósofos alemanes (Leibniz, Kant, Hegel) y británicos (Hobbes, Locke, Hume), como también de los librepensadores franceses (Montesquieu; Voltaire; Rousseau) que amenazaban a socavar el dominio colonizador de la Corona y la hegemonía de la Iglesia católica. ${ }^{20}$

18 Nota del editor: la Universidad de San Marcos es considerada la primera universidad de América, debido a que fue fundada en mayo de 1551 según la normatividad de la Corona española. La Universidad de Santo Domingo fue fundada por bula papal del 28 de octubre de 1538 y por Real Cédula del 26 de mayo de 1747, la que no reconocía valor jurídico a la fundación papal.

${ }^{19}$ La experiencia de la Reconquista sobre los moros en la Península española y la lucha teológica contra el protestantismo (la Contrarreforma) determinaron mucho la manera cómo se luchaba contra las idolatrías de los pueblos indígenas del Nuevo Mundo.

${ }^{20}$ No es casual que los representantes principales del racionalismo continental y del empirismo británico fueran protestantes (con la excepción del mismo René Descartes). El espíritu contrarreformista de los españoles y de los nuevos criollos en América impidieron que sus ideas tomaran cuerpo en las universidades, hasta el siglo XVIII. Lo mismo ocurrió con las 
Hasta mediados del siglo XVIII, las universidades latinoamericanas eran bastiones de la legitimación intelectual y científica del poder colonial, de la supuesta superioridad del espíritu europeo y de la fundamentación de la inferioridad de la raza india y mestiza. Las universidades estaban abiertas casi exclusivamente a la élite criolla masculina; es decir, eran centros de estudios de los españoles para los españoles, islas intelectuales en un mar agitado por olas de rebeldía y resistencia. Recién en la segunda mitad del siglo XVIII ciertas universidades introdujeron poco a poco las ideas seculares y modernas de los racionalistas europeos (y en menor medida de los empiristas británicos) y de los philosophes franceses de la Ilustración, con sus ideas revolucionarias de igualdad, libertad y fraternidad de los seres humanos.

Pero se trataba de un cambio meramente ideológico y formal del mismo sujeto criollo para luchar por la independencia política de la nueva oligarquía del yugo colonial, sin cambiar absolutamente nada referente a la inclusión de los mestizos y mucho menos de los indígenas en la producción del saber y el ejercicio del poder. La élite española era reemplazada por una élite criolla, con los mismos apellidos y los mismos títulos de propiedad. Durante la vida republicana las universidades seguían fungiendo como instrumento de poder de la clase alta y blanca, incluyendo poco a poco a los mestizos (mistis) como carne de cañón intelectual para la defensa de sus intereses. Había solo un relevo de intelectuales realistas por republicanos, a veces entre las mismas personas, pero sin alterar nada en la estructura colonial de las universidades y su mentalidad eurocéntrica y racista.

Las universidades en América Latina, junto a la Iglesia católica y el poder político criollo, han sido durante más de 400 años el sostén del proyecto de la denominada 'civilización occidental-cristiana', a través de una estrategia de imitación, adaptación e incorporación de las ideas y posturas filosóficas y teológicas vigentes en Europa (y posteriormente en Estados Unidos). Todos los intelectuales que querían aspirar a un título académico y al prestigio social correspondiente, tenían -y siguen en eso- que someterse a una circuncisión helénica ${ }^{21}$ rigurosa. Hasta en nuestros días, las universidades y la vida académica en el continente no han sido otra cosa que «un eco de una vivacidad

ideas ilustristas de los filósofos franceses, que indujeron a la población criolla a defender los principios de igualdad, libertad y fraternidad, en contra de la Corona.

21 Esta expresión (polémica) se refiere a la rendición de San Pablo ante las filosofías del helenismo, después de haber sido victorioso en su lucha contra la circuncisión judaica, en su diputa con San Pedro. Es parte de la tragedia de la historia del cristianismo de que la proclamada circuncisión interior por el Espíritu (Rm 2:29) para llevarnos a la libertad en Cristo, se ha convertido poco a poco en una sumisión intelectual al paradigma filosófico del helenismo. Consecuencias tangibles de esta circuncisión intelectual son (entre otros) el fuerte dualismo metafísico y antropológico, el desprecio por la sensibilidad, la corporeidad y la mundanidad, las distintas formas de sexismo y racismo, y un latente determinismo teológico. 
ajena» (Hegel), un anatopismo22 alienante y alienado, al servicio de una élite occidentófila y renegada con el mestizaje y la indianidad de su mundo.

A pesar de la etimología y de algunas prácticas del saber integral, la universidad europea (y sus dependencias en el Sur global) nunca ha sabido llegar a una universalidad de la verdad, en el sentido de la integración e inclusión de todos los sujetos cognoscitivos, tipos de saberes, métodos de investigación y su aplicación a la vida. Hasta hoy en día, en las universidades se enseña un cierto tipo de saber compatible con los parámetros de un canon científico establecido en Occidente, estudian y enseñan sobre todo miembros de las clases alta y media — de preferencia de sexo masculino y de tez blanca-, y se utilizan métodos establecidos dentro de la tradición dominante de la filosofía occidental. ${ }^{23}$

\section{Un enfoque intercultural de la epistemología}

La filosofía intercultural ha puesto de manifiesto el carácter monocultural y eurocéntrico de lo que es el modelo estándar de la universidad. Si uno estudia en Shanghai, Nairobi, Nueva York, Lima o Delhi, el currículo de los estudios académicos, los títulos universitarios, los estándares de investigación, la terminología técnica y el procedimiento en la construcción del conocimiento son más o menos idénticos. Esta uniformización de los estudios universitarios se defiende en nombre de una academicidad universal, sustentada por una supuesta supra-culturalidad de los contenidos, métodos y estándares académicos. $^{24}$

El enfoque intercultural cuestiona esta supuesta supra-culturalidad y universalidad $^{25}$ de la vida académica de la gran mayoría de las universidades,

\footnotetext{
${ }^{22}$ Víctor Andrés Belaúnde (1889-1966) acuñó en sus Meditaciones Peruanas (1917) el término anatopismo para resaltar el carácter des-contextualizado del pensamiento latinoamericano que simplemente trasplanta la filosofía occidental al suelo (topos) americano, sin tomar en cuenta la propia realidad y el contexto específico de América Latina.

${ }^{23}$ La inclusión paulatina de mujeres e indígenas en las universidades latinoamericanas no cambió mucho de principio, sino que fundamentaba aún más el espíritu occidentalizado, porque seguían con el requisito de una circuncisión helénica y del androcentrismo conceptual y metodológico. Lo mismo se puede decir de la gran mayoría de los seminarios teológicos, tanto católicos como protestantes, que siguen imitando y reproduciendo una teología europea clásica.

${ }^{24}$ Hoy, en la era de la globalización neoliberal cultural y cibernética, se nota una nueva ola de uniformización de los contenidos y procedimientos académicos, que viene a ser una anglosajonización de los títulos y métodos, tal como ${ }^{\circ}$ curre en Europa con la implementación del Consenso de Bolonia, o como ocurre en las universidades de América Latina con los títulos de bachillerato y masters.

${ }^{25}$ Mientras la supra-culturalidad sostiene que la universalidad fuera el fruto de ideas y
} 
revelándola como culturalmente determinada, contextual, históricamente identificable e ideológica. La academicidad universal —con todos sus códigos, parámetros y formalidades - se delata como fuertemente occidentocéntrica e instrumental, en el sentido de ser el vehículo ideológico de los valores culturales e intereses económicos y políticos de Occidente.

La concepción dominante de la universidad y del conocimiento (epistemología dominante), incluso en América Latina y en la mayor parte de la periferia (Sur global), refleja algunos presupuestos culturalmente enraizados en la tradición filosófica y cultural occidental. Entre ellos, podemos mencionar:

a. Saber es poder. Este lema de Francis Bacon(1561-1626) ha determinado gran parte de la vida académica de las universidades. El saber es considerado un depositum, una riqueza o un capital intelectual en el poder de unos pocos letrados e iluminados. Hoy en día, se suele hablar de la acumulación de conocimientos o del capital intelectual (sobre el que hay derecho de propiedad), tal como se habla de la acumulación de capital o de ahorros. En todas las épocas, el saber ha sido utilizado para dominar a la población iletrada e ignorante. La traducción de la Biblia por Lutero al alemán rompió con un tabú de la inteligentsia eclesial y clerical, sin por ello quitar el poder de los letrados y estudiosos (no había todavía mujeres letradas) hasta hoy en día.

b. Predominio de la analiticidad. A partir de la modernidad europea se impone el análisis como método ortodoxo y predominante de las investigaciones académicas, basado en la biblia de la modernidad el Discurso del Método de René Descartes. La analiticidad pretende llegar al conocimiento del mundo a través de una descomposición real o imaginaria de lo que no se puede o no se debe descomponer. En el caso de la vida, la descomposición (análisis) llega a causar la muerte del organismo descompuesto, sin la posibilidad de ser recompuesto (síntesis). ${ }^{26}$

c. Compartimentalización del saber. Las universidades han llegado a través del tiempo a una compartimentalización del saber cada vez

normas existentes más allá de cualquier contexto cultural o civilizatorio, es decir: como idea platónica-, la universalidad intercultural apuesta por una negociación intercultural de saberes y conocimientos y el fruto empírico siempre provisional de ella.

${ }^{26}$ Me parece que el afán de separar y depurar analíticamente los diferentes aspectos de la realidad es una característica típicamente masculina. Yo (como varón) lo practico también, en este mismo trabajo. Y no está mal de por sí; solo que se vuelve neurótico y devastador si este modelo androcéntrico de concebir y manejar el mundo se convierte en el único posible, en el paradigma universalmente válido, en la vía única verdadera de salvación. 
más honda y radical. La ramificación sofisticada de los conocimientos en disciplinas (¡sic!), sub-disciplinas y especializaciones ha producido en el mismo mundo científico una confusión y desentendimiento babilónico alarmante. ${ }^{27}$ El homo academicus es un especialista desarticulado, desubicado y totalmente desvinculado de la realidad holística y relacional. El rigor académico se mide por el grado de especialización y la aplicación de un método tan particular que ya no hay comunicabilidad con otros compartimentos del saber.

d. Objetividad ideológica. En la gran mayoría de las universidades, sigue en pie el ideal de una objetividad con pretensión supra-cultural y universal. Cualquier referencia al punto de vista subjetivo del o de la observador, investigador o docente es vista como una violación de este principio y como una particularización y contextualización de un saber supuestamente universal. Desde el enfoque intercultural, cada saber universal es situado, contextualizado y subjetivizado, es decir: culturizado, y la llamada 'objetividad' nunca puede ser un a priori meta-cultural, sino el ideal heurístico de un sinnúmero de polílogos interculturales. La crítica feminista a las epistemologías dominantes, por ejemplo, ha demostrado, que bajo el manto de la objetividad y universalidad, se ha impuesto un modelo androcéntrico del saber.

e. Androcentrismo universitario. Si bien es cierto que las universidades se han abierto — en los últimos cincuenta años- a las mujeres, las estructuras jerárquicas, la conceptualización del conocimiento, el procedimiento estándar, los códigos académicos y el lenguaje técnico siguen reflejando una fuerte visión e ideología androcéntrica. Se habla del 'rigor' científico, de la 'consistencia' lógica, de la 'imparcialidad' académica, del carácter 'analítico' del pensamiento, de la 'cuantificabilidad' de los fenómenos y de los 'títulos' académicos, todos estos elementos de una mentalidad y concepción predominantemente masculina (Estermann 2006).

f. Escrituralidad de los conocimientos. Occidente ha fomentado una cultura universitaria centrada en el texto como fuente básica de referencia y comprobación científica en la construcción de saberes. Podemos hablar de una mentalidad rumiante: el conocimiento como

${ }^{27}$ La terminología delata: Hablar de disciplinas científicas significa no solo el disciplinamiento del saber, sino de los que pretenden adquirirlo y usarlo de manera libre (Patzi 2003). Raimon Panikkar (1997), por su parte, habla de la «manía clasificatoria» de Occidente; mediante la diéresis, Occidente viene intentando, desde Sócrates, conquistar intelectualmente al mundo entero. Las definiciones incluyen o excluyen, según los criterios de los/as que definen. 
una serie de interpretaciones de interpretaciones de textos. ${ }^{28} \mathrm{La}$ base textual tiene para la Academia la misma rigidez y ortodoxia que el Texto Sagrado para un creyente. La liturgia académica de usar abundantes referencias bibliográficas coincide con el ideal de erudición que se basa en la recepción de innumerables volúmenes de textos escritos.

g. El fetiche de los títulos académicos. Los títulos académicos que otorgan las universidades, sirven de moneda universal de cambio - tal como el dólar - para el prestigio y renombre de las personas que los poseen. A través de la titulación se crea una oligarquía o élite académica, una suerte de logia que no utiliza sus saberes para el bien de la gran mayoría de la humanidad, sino para su bien y provecho propio. Esto se agrava cada vez más por la carrera loca de publicar (publish or perish), prerrequisito para tener una carrera en las universidades estadounidenses y europeas. Las universidades están lejos de la idea que Platón planteó en su Parábola de la Caverna de que los iluminados deberían bajar nuevamente a las profundidades de la miseria humana, en un acto solidario, para liberar a los cautivos. ${ }^{29}$

h. Universidades como rehenes de la ideología del mercado. Las universidades con fines de lucro ofrecen carreras al servicio de la ideología neoliberal globalizadora, con tal de que sus saberes se conviertan en mercancía y sus actores en competidores y productores. La terminología delata de manera reveladora la nueva era de la vida universitaria: se habla de 'producción de conocimientos', de la 'libre demanda y oferta', del 'mercado académico' y de la 'competitividad intelectual'. ${ }^{30}$

i. Desvinculación de la sociedad civil. Muchas universidades siguen siendo islas en un mar de convulsiones sociales, luchas indígenas, deterioro de la naturaleza y pobreza e injusticia cada vez más pronunciadas. Por eso, se hacen cómplices voluntarios o involuntarios del status quo y de las élites conservadoras de las sociedades nacionales, traicionando a

\footnotetext{
${ }^{28}$ Nietzsche habló de una filosofía rumiante, al referirse a un historicismo exagerado y una filosofía que ha perdido el contacto con la realidad y se dedica únicamente a la interpretación de textos.

${ }^{29}$ Basta observar las ceremonias de graduación en EE.UU. y los países satélites. Se viene introduciendo estas costumbres con cada vez más peso en América Latina.

${ }^{30}$ La mayoría de las universidades particulares en América Latina - y en el resto del mundo- ya no ofrecen estudios humanísticos, porque estos son considerados poco rentables. Incluso universidades confesionales, sean católicas o evangélicas, priorizan las carreras de Administración de Empresas, Economía y Comunicación; lo religioso, filosófico y espiritual funge de taparrabo dentro de una mentalidad totalmente neoliberal (competitividad, rentabilidad, eficiencia, cuantificabilidad etcétera).
} 
los sujetos subalternos y marginados, discriminados y eternamente postergados.

\section{Conocimiento en clave andina}

En su gran obra Epistemología del Sur, ${ }^{31}$ el sociólogo portugués Boaventura de Sousa Santos (2009) plantea una serie de alternativas a este modelo dominante de la producción y manejo del conocimiento, tal como se viene imponiendo en gran parte del mundo globalizado a partir del Renacimiento europeo. La Epistemología del Sur, como una de las epistemologías emergentes, descansa sobre dos propuestas que coinciden con los principios de la Filosofía Intercultural. Primero, que «la comprensión del mundo es mucho más amplia que la comprensión occidental del mundo. Esto significa, en paralelo, que la transformación progresista del mundo puede ocurrir por caminos no previstos por el pensamiento occidental, incluso por el pensamiento crítico occidental (sin excluir el marxismo)» (De Sousa Santos 2009: 35). Segundo, que la diversidad del mundo es infinita y que «incluye modos muy distintos de ser, pensar y sentir, de concebir el tiempo, la relación entre seres humanos y entre humanos y no humanos, de mirar el pasado y el futuro, de organizar colectivamente la vida, la producción de bienes y servicios y el ocio.» (De Sousa Santos 2009: 35).

31 «Asimismo, existen otras oportunidades que se formulan de otra manera; son oportunidades poscapitalistas: pueden producirse dentro del propio sistema capitalista; pueden ser oportunidades con vocación poscapitalista (Venezuela, Bolivia, Ecuador); u oportunidades posoccidentales, como lo que estamos viendo en el mundo árabe. No sabemos lo que van a ser; tampoco cuál será finalmente su orientación política, pero está claro que esta lucha por algo, en algunos lugares poscapitalistas y posoccidentales, está en la agenda de algunos países.» (De Sousa Santos 2009: 13). En Epistemologías del Sur de 2011 plantea también: «Es un hecho irreversible que el logos eurocéntrico ha implosionado en sus propias fuentes de desarrollo político y económico. El peligro de esta crisis es total porque abarca su hegemonía y a la humanidad y a la naturaleza. ¿De qué alternativas disponemos para superar este fin de milenio y su hecatombe? Es evidente que estamos viviendo los "tiempos póstumos" o de "filosofía finisecular" de una Modernidad que luce, por otra parte, rebasable desde otra episteme histórico-cultural que reconozca la relación ecosistema del hombre en el conjunto de la diversidad existencial de los seres vivos que pueblan este planeta. Esta otra epistemología que tiene su génesis en la Teoría Crítica y se recrea en América Latina, desde el Sur, se asume desde la praxis de un logos emancipador que fractura los límites hegemónicos del "capitalismo sin fin" y del "colonialismo sin fin", ya que hace posible recuperar desde la "sociología de las emergencias", la presencia de los pueblos milenarios que han logrado la recreación de su hábitat a través de una relación simbiótica directa, con los ciclos o procesos de génesis y muerte de la Madre Tierra (Pachamama). La sabiduría ancestral que porta el pensamiento de estos pueblos originarios, expresados por sus tradiciones, ritos, magias, hasta sus representaciones antropomórficas de la realidad, son síntomas de que el ocaso de la civilización, no muere con Occidente, sino que renace desde el Sur con el Sumak Kawsay» (De Sousa Santos 2011: 17) 
Una de las epistemologías alternativas emergentes - y al mismo tiempo milenaria- es la epistemología andina. El rol y la función del conocimiento dentro de la Filosofía Andina no es algo que se puede establecer y estudiar de modo separado de lo que es la pachasofía o la sabiduría andina acerca del pacha, en general; esta no presupone el hiato originado en la filosofía occidental moderna entre el ser y el conocer, entre ontología y epistemología que repercute, en última instancia, en la escisión entre sujeto y objeto, o en terminología cartesiana, entre res cogitans y res extensa. El conocer (yachay; yatiña) en la cosmo-espiritualidad andina no es algo que se añade al ser y tampoco se limita al ser humano como conocedor o fuente de conocimiento. Comparable con la idea leibniziana de que todo tiene percepción, desde las mónadas más simples hasta la monada monadarum (Dios), en el mundo andino todo participa en la tarea epistemológica, porque todo refleja de cierta manera la relacionalidad del pacha como rasgo fundamental del serconocer. Este principio tiene que ver, en el caso de la Filosofía Andina, con la concepción de que la vida (kawsay, qamaña) es un principio trascendental, es decir, una característica de todos los seres. Por lo tanto, inclusive minerales y astros tienen conocimiento, lo que no dista mucho de los últimos hallazgos de la física contemporánea, según la que, por ejemplo, el agua tiene memoria.

El ser humano destaca en esta cadena del conocer (en alusión a la cadena del ser de la que habla Plantinga) por su poder representativo y simbólico en la tarea de establecer chakanas gnoseológicas entre diferentes ámbitos de la vida (arriba y abajo, pasado y futuro, femenino y masculino, etcétera). Esta representación puede tomar diversas formas, de las que la abstracción intelectual en el concepto es solamente una. El ritual, la celebración, los bailes, la curación, el arte, la agricultura, la espiritualidad, el ritmo musical, la estructuración política: todos ellos son modos de conocimiento, instrumentos del saber andino. Un yatiri ('el que sabe') o paqu andino (chamanes o especialistas rituales) no poseen un conocimiento esotérico, sino que se apoyan de manera óptima en la sensibilidad humana en el contacto con los elementos, dialogando con el viento, el cerro y los astros, entrando en contacto con el mundo espiritual de los apus/achachilas, ancestros y protectores, y restableciendo la relacionalidad dañada o entrecortada.

Retomando los puntos mencionados con respecto a la epistemología occidental dominante, podemos concluir, en perspectiva intercultural, que el conocimiento en perspectiva andina y la epistemología andina obedecen a los siguientes principios:

a) Saber no es poder, sino un instrumento para alcanzar un grado más intenso y universal de la vida. En este sentido, el ideal del buen vivir andino (allin kawsay; suma qamaña) no puede ser realizado en 
forma de privación (solo para algunos pocos), sino siempre en forma holística. El saber de los chamanes andinos no es un saber esotérico que se guarda para ejercer su poder sobre los ignorantes, sino es un saber al servicio de la vida, no solo de los seres humanos, sino de todo el pacha.

b) Predominio de la sinteticidad. Como la relacionalidad forma el principio básico y la garantía para la vida en sus dimensiones cósmicas, el conocimiento de las partes, es decir de entes más o menos aislados no constituye ideal alguno, sino al revés. El conocimiento analítico no nos lleva a mayor conocimiento, sino a escisiones de todo tipo, a una división de la realidad (pacha) en todos los niveles y ámbitos, y, por lo tanto, a un alejamiento de la vida. Entender en perspectiva andina es comprender holísticamente la estructura relacional de la realidad en un acto sintético o integral; el análisis es más bien un paso secundario, muy al contrario del procedimiento cartesiano. En última instancia, el principio de la sinteticidad epistemológica andina responde a la organicidad de la realidad (y no a la mecanicidad de la res extensa). Comprender la vida es entender la multiplicidad de relaciones en que se desenvuelve.

c) Descompartimentalización del saber. Una universidad andina no debería de ser organizada en torno a disciplinas o facultades. El gran reto para el siglo XXI no consiste en la especialización y la profundidad de lo específico y parcial, sino en la articulación de ámbitos considerados por la modernidad occidental como incompatibles: lo religioso y lo tecnológico, lo ritual y lo conceptual, lo biológico y lo físico, lo humano y lo no-humano, el pasado y el futuro, lo material y lo espiritual. El conocimiento en sentido andino siempre es inter y transdisciplinario. Por tanto, incrementar el conocimiento no significa acumular información acerca de lo particular y aislado, sino ampliar y reforzar los lazos entre diferentes ámbitos del saber y de la vida; y esto significa, en última instancia, superar las escisiones impuestas por las ciencias occidentales y la organización del saber en facultades $\mathrm{y}$ disciplinas.

d) Relacionalidaden vez de objetividad. Elideal de la modernidad occidental y de las ciencias surgidas en esta época favorece la objetividad en el sentido de que aquel conocimiento fuese el más confiable y digno de conseguir que tenga un valor independientemente del observador subjetivo. Como en la epistemología andina no existe la escisión entre sujetoy objeto, nila objetividad nila subjetividad constituyen referentes para el grado y la confiabilidad de conocimientos. Un conocimiento en perspectiva andina es más confiable y de mayor importancia, si 
y en la medida en que sabe representar la relacionalidad de todo, es decir la estructura relacional del pacha. El ideal gnoseológico no es la objetividad (que inclusive en Occidente es un sueño ideológico), sino la articulación óptima de ámbitos y niveles. En perspectiva intercultural, un saber que incluye otras perspectivas culturales y civilizatorias tiene mayor grado de confiabilidad que un conocimiento construido a partir y dentro de la monocultura. La universalidad solo se alcanza mediante un proceso empírico de múltiples diálogos (o polílogos) interculturales, y no como un supuesto a priori monocultural.

e) Perspectividad gino-androcéntrica. La complementariedad sexuada de dimensiones cósmicas — entre lo 'femenino' (warmi) y lo 'masculino' (qhari/chacha) - rechaza todo tipo de conocimiento que refleja una perspectiva única, sea andro o ginocéntrica. Esto no quiere decir necesariamente que varones y mujeres tengan el mismo acceso gnoseológico ni que su participación fuera absolutamente equitativa en la educación, política y economía, sino que los acercamientos ginófilos y andrófilos se complementan en la construcción de conocimientos. Así, una perspectiva ginófila (que puede ser adoptada tanto por mujeres como por varones) favorecerá métodos holísticos, integrales, orgánicos y articuladores, y una perspectiva andrófila se inclinaría más a métodos analíticos, mecánicos, clasificatorios, cuantitativos y parcializadores. La titulación en la educación formal debería de incluir aspectos emocionales, sociales, espirituales, empáticos, de cuidado y de integración, junto a cognoscitivos, discursivos, conceptuales y performativos.

f) Simbolicidad de los conocimientos. El vehículo de los conocimientos y de las ciencias en la modernidad occidental es el texto, sea físico o digital, bibliográfico o electrónico. El conocimiento andino se trasmite a través de una larga tradición oral y mediante vehículos rituales, espirituales y representaciones artísticas, cuya característica principal no es la logicidad discursiva, sino la simbolicidad metafórica. El texto solo sirve de sustento auxiliar, pero no contiene el conocimiento como si se tratara de una bóveda bancaria. Para el último Inca Atawallpa, la Biblia que le presentó el Padre Valverde no podía contener el conocimiento acerca de lo divino. Para la educación formal, esto significa que aparte de textos y la lecto-escritura se debe fomentar y promover otros tipos de envases de los conocimientos que incluyan también otros sentidos que la vista y el oído.

g) El Buen Vivir como criterio epistemológico. La universidad moderna occidental se viene alejando cada vez más de la promoción de la vida como su objetivo principal y se subordina al dictado de la rentabilidad, de la maximización de las ganancias. Para la perspectiva andina, 
el conocimiento no es un instrumento para el enriquecimiento y la acumulación del capital intelectual (en sentido de la propiedad intelectual), sino un instrumento al servicio de la vida en su forma armoniosa y en equilibrio con todos los niveles y aspectos, en pasado, presente y futuro. El Buen Vivir (allin kawsay, suma qamaña) no es otra cosa que el con-vivir armonioso en dimensiones cósmicas y en perspectiva sostenible. El conocimiento que no contribuye a ello, puede ser interesante en el mejor de los casos, o nocivo y destructor en el peor, pero no contribuye a la conversación y evolución integral del pacha como vida (kawsay, qamaña).

h) Formación más que información. Según el mainstream mediático, estamos actualmente en la era de la información. Los medios sociales de comunicación nos brindan testimonio de la inmensa cantidad de información (big data) que se acumula en el ciberespacio. Proporcionalmente a lo inverso se pierde la formación en un sentido integral del ser humano, incluyendo todas las facetas físicas, psíquicas, habituales, espirituales y afectivas. En las universidades, las carreras rentables son las más favorecidas y co-financiadas por el sector privado, en especial las grandes empresas transnacionales. Esto mantiene a las universidades en condición de rehenes por el capital global y les impide pronunciarse por el deterioro ambiental, la violación de los derechos humanos, la pérdida de la biodiversidad y el surgimiento de una sociedad re-feudal y anti-democrática. El conocimiento andino es formativo más que informativo, porque procura articular lo teórico con lo práctico, lo fáctico con lo normativo, lo objetivo con lo político, lo local con lo global, lo humano con lo extra-humano, lo material con lo espiritual.

i) Reintegración socio-política. El conocimiento en perspectiva andina ni es privado ni un monopolio de una élite, sino patrimonio de todos, incluyendo la naturaleza; no es un fin en sí mismo, sino un instrumento para mantener o restablecer el equilibrio pachasófico y garantizar, de esta forma, la vida en sus diferentes dimensiones y aspectos. En este sentido, el conocimiento nunca es neutral. Pensadores como Foucault o Habermas han demostrado que el complejo científico-tecnológico en Occidente obedece a intereses de poder político, económico y militar, bajo el manto de la imparcialidad ideológica. El conocimiento en perspectiva andina desde su elaboración y construcción tiene implicaciones políticas y sociales, económicas y ecológicas, porque su norte es el Buen Vivir y no la mejor vida de algunos pocos. Las crecientes desigualdades tanto en un nivel global como nacional y regional son un atentado frontal al ideal andino del Buen Vivir y los principios epistemológicos contenidos en la pachasofía andina. 


\section{A manera de conclusión}

El gran reto que afronta el mundo en el siglo XXI no es la acumulación indefinida de los conocimientos (big data), sino la articulación de los mismos con la vida, tanto del ser humano como del planeta Tierra y del cosmos en su totalidad. Ya sabemos lo suficiente como para entender el funcionamiento real del mundo, pero somos todavía analfabetos en comprender este gran organismo llamado Gaia o Pacha, esta red relacional de conexiones vitales a lo largo de la historia y a lo ancho de las culturas y civilizaciones. Se requiere, por lo tanto, de un conocimiento integral e integrador, un conocimiento sentipensante, un conocimiento cosmo-espiritual, un conocimiento más ginófilo que androcéntrico, un conocimiento pachasófico en vez de logocéntrico y tecnomorfo.

La Filosofía Andina contribuye con sus principios a esta tarea de la humanidad y me parece que el ideal del Buen Vivir o Vivir Bien (allin kawsay; suma qamaña) puede servir de modelo heurístico y de fundamento orientador de una nueva epistemología que no se separa de la ética, sino que la presupone. Sin relación no hay vida, sin vida no hay relación. El enfoque intercultural asegura, además, que no se incurre en otro tipo de centrismo cultural o civilizacional. Por eso, la epistemología del siglo XXI será intercultural, relacional y holística, si la humanidad realmente quiere sobrevivir, junto a la Naturaleza, el mundo espiritual y todo el legado de generaciones anteriores y futuras. 


\section{Referencias}

Belaúnde, Víctor Andrés (1917; 1987). Obras Completas. Tomo II. Meditaciones Peruanas. Lima: Comisión Nacional del Centenario.

De Sousa SANTos, Boaventura (2009). Epistemología del sur. México: Siglo XXI.

De Sousa SAntos, Boaventura (2011). "Epistemologías del Sur". En: Utopía y Praxis Latinoamericana. Año 16, №. 54, pp. 17-39.

ESTERMANN, Josef (2006). «La filosofía andina como alteridad que interpela: Una crítica intercultural del androcentrismo y etnocentrismo occidental». Concordia 49. Aachen: Wissenschaftsverlag Mainz, pp. 81-104.

Estermann, Josef $(1998,2018)$. Filosofía Andina: Estudio intercultural de la sabiduría autóctona andina. Lima-Cusco: Paulinas, Seminario San Antonio Abad.

Gómez NAVARRETE, Javier (1998).«Construcción del conocimiento en América Latina y el Caribe». Primer Simposio Internacional, Universidad de Quintana Roo. Manuscrito no publicado.

Madrigal Frías, Luis (2011). «Educación del Poder. Los Mayas Prehispánicos». XI Congreso Nacional de Investigación Educativa/12. Multiculturalismo y Educación/Ponencia. Consejo Mexicano de Investigación Educativa, A.C. México.

PANIKKAR, Raimon (1997). La experiencia filosófica de la India. Madrid: Trotta.

PATzi, Félix (2003). Etnofagia estatal: Modernas formas de violencia simbólica (Análisis de la Reforma Educativa en Bolivia). La Paz: PIEB. 